\title{
ANÁLISE DA PERCEPÇÃO AMBIENTAL DOS FREQUENTADORES DA ÁREA VERDE DOM CONSTANTINO LUERS, NO MUNICÍPIO DE ARAPIRACA-AL
}

\author{
ANALYSIS OF THE ENVIRONMENTAL PERCEPTION OF USERS OF THE GREEN \\ AREA DOM CONSTANTINO LUERS, IN THE CITY OF ARAPIRACA-AL
}

\author{
Renata Rodrigues da Costa ${ }^{1}$, Maria Gleysiane Souza dos Santos ${ }^{2}$, Rosineide Nascimento da Silva ${ }^{3}$
}

\section{RESUMO}

Os espaços públicos arborizados são áreas verdes que podem desenvolver funções ecológicas, sociais, de lazer e contribuir para a melhoria da qualidade ambiental e de vida da população. Assim, a percepção do homem sobre o ambiente no qual está inserido é muito importante, pois pode auxiliar na proteção e no cuidado desse local. $O$ objetivo desse estudo foi analisar a percepção ambiental dos frequentadores da Área Verde Dom Constantino Luers, localizada na cidade de Arapiraca-AL, além de conhecer seu perfil sociodemográfico e as formas de utilização do espaço pelos frequentadores. Para isso, foram entrevistados 56 frequentadores, de abril a maio de 2019, através da aplicação de questionário, que abrangeu os seguintes aspectos: perfil sociodemográfico, hábitos de utilização do espaço pelos frequentadores e sua percepção ecológica e conservacionista. Dentre os frequentadores, $57,15 \%$ foram mulheres e a faixa etária mais representativa estava entre 50 a 69 anos (44,64\%). A área verde é utilizada por $50 \%$ dos frequentadores para a prática de esportes. Quanto a conservação do local, 39\% dos frequentadores perceberam que o estado de conservação do mesmo é regular. Conclui-se que, são necessárias estratégias para melhorar a arborização e o estado de conservação da área verde.

Palavras-chave: Ecologia; Espaço público; Ambiente; Cidade.

\begin{abstract}
Wooded public spaces are green areas that can develop ecological, social, leisure functions and contribute to the improvement of the environmental quality and life of the population. Thus, the human's perception about the environment in which he is inserted is very important, as it can help in the protection and care of this place. The objective of this study was to analyze the environmental perception of visitors of the Dom Constantino Luers Green Area, located in the city of Arapiraca-AL, besides knowing its sociodemographic profile and the forms that visitors use the space. For this, 56 participants were interviewed, from April to May 2019, through the application of a questionnaire, which covered the following aspects: sociodemographic profile, habits of space use by the visitors and their ecological and conservationist perception. Among the participants, $57.15 \%$ were women and the most representative age group was between 50 and 69 years old (44.64\%). The Green Area is used by $50 \%$ of the visitors for sports practices. Regarding the conservation of the site, $39 \%$ of visitors realized that its state of conservation is regular. It is concluded that, strategies are needed to improvement afforestation and conservation status of the Green Area.
\end{abstract}

Keywords: Ecology; Public space; Environment; City.

\footnotetext{
Recebido em 14.07.2019 e aceito em 05.02.2020

1 Aluna do Curso de Ciências Biológicas. Universidade Estadual de Alagoas. Arapiraca/AL. Email: renivdl.rodrigues@gmail.com

${ }^{2}$ Aluna do Curso de Ciências Biológicas. Universidade Estadual de Alagoas. Arapiraca/AL. Email: gleeysiane@gmail.com

${ }^{3}$ Bióloga licenciada. Mestra em Ecologia e Conservação. Docente da Universidade Estadual de Alagoas. Arapiraca/AL. Email: rosineideg7@gmail.com
} 


\section{INTRODUÇÃO}

No Brasil, o processo de crescimento urbano vem ocorrendo de forma desenfreada e desordenada pela ineficiência das políticas públicas de planejamento das cidades. Quando o ambiente urbano se expande sem planejamento, acaba colaborando não só para a ocorrência de problemas de saúde pública, mas também para a degradação do ambiente e perturbação de áreas verdes. Assim, temas envolvendo medidas de conservação de áreas verdes urbanas tem sido alvo de discussões na literatura (SOARES et al., 2014).

Os espaços públicos assumem novos significados nas cidades do século $\mathrm{XX}$. Os espaços públicos, lugares voltados para o espetáculo e o entretenimento, surgem na cidade do século XX com "resiginificados", ou seja, com novas conotações simbólicas e valores (DIAS, 2005). Por outro lado, alguns espaços são concebidos como áreas verdes pelo fato de promoverem a arborização e reforçar a ideia de conservação e preservação da biodiversidade (PINA; SANTOS, 2012). Dessa forma, esses espaços têm como funções: equilibrar a relação entre espaço modificado pela urbanização e o meio ambiente; incentivar relações de vivência e coletividade de uma comunidade; e realizar práticas de lazer e esportes (JATOBÁ, 2011).

Uma área verde pode ser considerada como um indicador de qualidade de vida, pois o bem-estar de uma população pode estar na prática de frequentar lugares mais arborizados. É, cientificamente, comprovado que esse contato interfere de forma positiva na vida dos citadinos, uma vez que essas áreas podem desenvolver funções ecológicas, sociais e de lazer, contribuindo para a melhoria da qualidade ambiental e de vida da população (LONDE; MENDES, 2014).

Diferentes percepções são despertadas em determinados espaços. Quando uma pessoa frequenta uma área ou espaço, provoca vários tipos de percepções, que podem estar calcadas no estímulo e na informação que o local gera em cada observador (LOBODA; ANGELIS, 2005). Para esses autores, a diferença entre estímulo e informação torna-se clara quando se leva em consideração o contexto da informação visual, ou seja, o estímulo é um padrão de energia que é apenas registrado pelos órgãos dos sentidos, já a informação, sob o ponto de vista da abordagem ecológica, está relacionada a existência (e as características) de objetos e eventos que o observador percebe e é resultante do tratamento de dados, de tal forma que haja uma modificação no conhecimento do sistema que a recebe.

A percepção do homem no que tange ao ambiente no qual ele está inserido é importante, pois além de avaliar as diferentes formas de uso dos recursos naturais, é um meio usado em algumas áreas do conhecimento para viabilizar a melhoria da qualidade de vida do homem, podendo ser definida como uma forma de sensibilização dele próprio, ou seja, o ato de 
perceber o ambiente no qual se está inserido faz com que o homem possa aprender a proteger e a cuidar do seu meio (MARIN, 2003).

Vale salientar que, os estudos de percepção são importantes, uma vez que, a investigação e a compreensão de sentimentos têm um papel de destaque na formação de juízos de valor e atitudes que orientam ações sobre diferentes espaços (COSTA; COLESANTI, 2011). Para esses autores, o estudo da percepção pode ser direcionado para as áreas verdes visando assim, compreender os valores atribuídos a estas áreas pela população. Desse modo, a percepção ambiental é um possível caminho a ser percorrido nos estudos acerca das áreas verdes públicas como praças, parques e jardins, buscando contribuir com informações relevantes para a conservação e/ou manutenção e multiplicação destes espaços no meio urbano como uma forma de garantir às comunidades um espaço agradável de convívio social (COSTA; COLESANTI, 2011; DORIGO; LAMANO-FERREIRA, 2015).

Há poucos trabalhos relacionando a percepção do homem sobre as florestas urbanas (ZARDIN et al., 2017), o que pode justificar o interesse no desenvolvimento deste estudo, tendo em vista que não se conhecem trabalhos relativos à análise da percepção dos frequentadores da Área Verde Dom Constantino Luers.

Nessa perspectiva, esse trabalho teve como objetivo investigar a percepção ecológica e conservacionista dos frequentadores da Área Verde Dom Constantino Luers, localizada no município de Arapiraca $(A L)$, além de conhecer o perfil sociodemográfico dos frequentadores e as formas de utilização do espaço.

\section{MATERIAL E MÉTODOS}

\section{Área de estudo}

No Nordeste Brasileiro (Figura 1A), situa-se o Estado de Alagoas (Figura 1B) e, na região central desse estado, na Mesorregião do Agreste Alagoano, localiza-se o município de Arapiraca (Figura $1 \mathrm{C}$ ), que é o de maior importância econômica e demográfica do interior de Alagoas (GOMES et al., 2012; GOMES; SILVA; FERREIRA, 2015). 

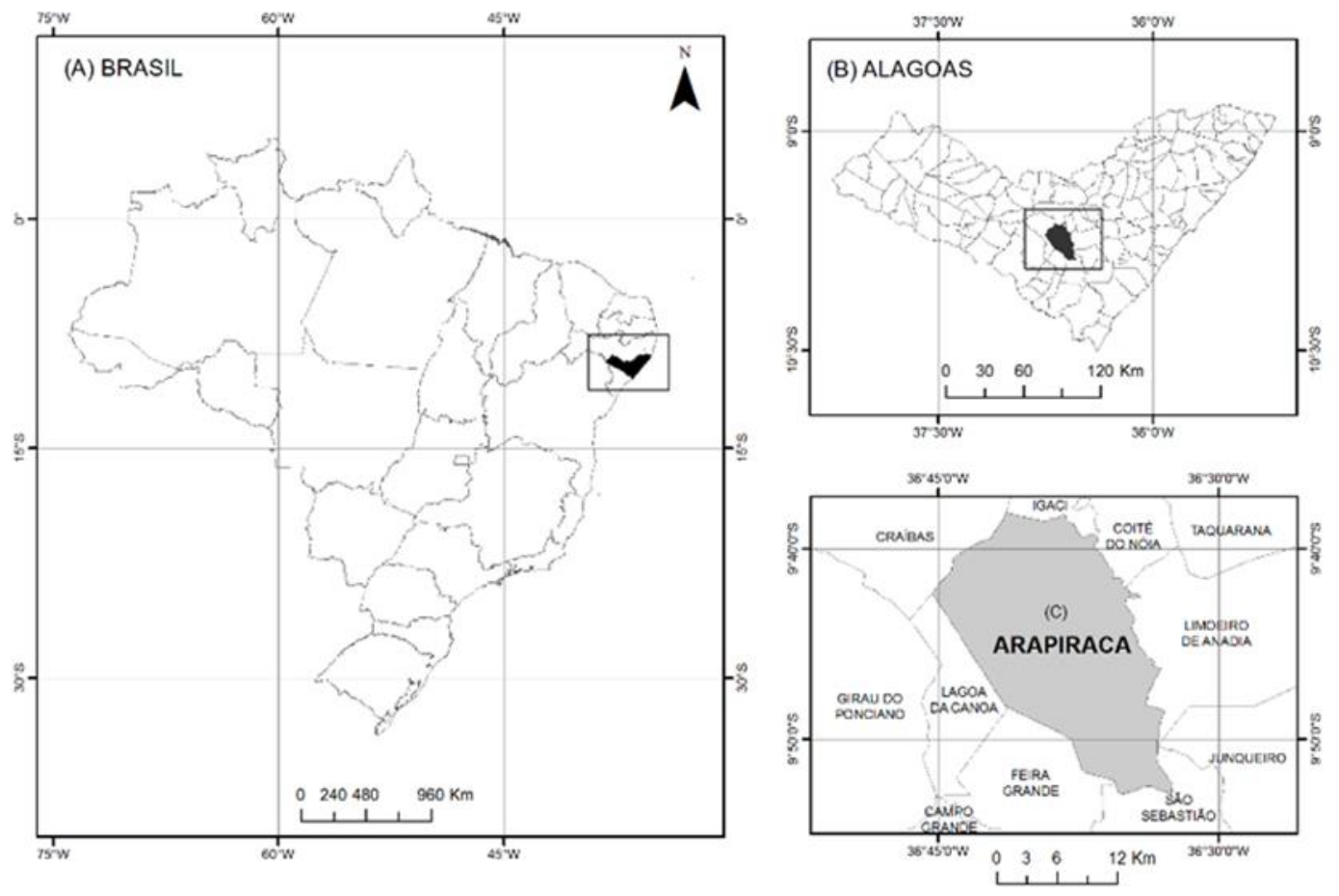

Fonte: Gomes, Silva e Ferreira (2015).

Figura 1. Representação parcial da Região Nordeste do Brasil (A), da localização do Estado de Alagoas (B) e do município de Arapiraca (C)

Figure 1. Partial representation of the Northeast Region of Brazil $(A)$, of the location of the State of Alagoas (B) and the municipality of Arapiraca (C)

O município tem uma extensão territorial de $345,65 \mathrm{Km}^{2}$ e uma população de 230.417 mil habitantes (IBGE, 2018). Possui altitude aproximada de $264 \mathrm{~m}$; relevo integrante da unidade dos Tabuleiros Costeiros, com altitude média de 50 a 100m; clima tropical chuvoso com verão seco; precipitação pluviométrica com média anual de $1.634 \mathrm{~mm}$; vegetação predominantemente de Floresta Subperenifólia, com partes de Floresta Subcaducifólia e Cerrado/Floresta (MASCARENHAS; BELTRÃO; SILVA JÚNIOR, 2005).

Em Arapiraca, a Área Verde Dom Constantino Luers (Figura 2) perpassa por dois diferentes bairros. Integrada à malha urbana desse município, a Área Verde, situada às margens da Av. Deputada Ceci Cunha, atravessa os bairros Novo Horizonte e Santa Esmeralda. Esse espaço público foi criado em 2005, possui 900 metros de extensão, é arborizado com árvores nativas e plantas ornamentais, possui bancos e parquinhos, entre outros (PMA, 2019). 


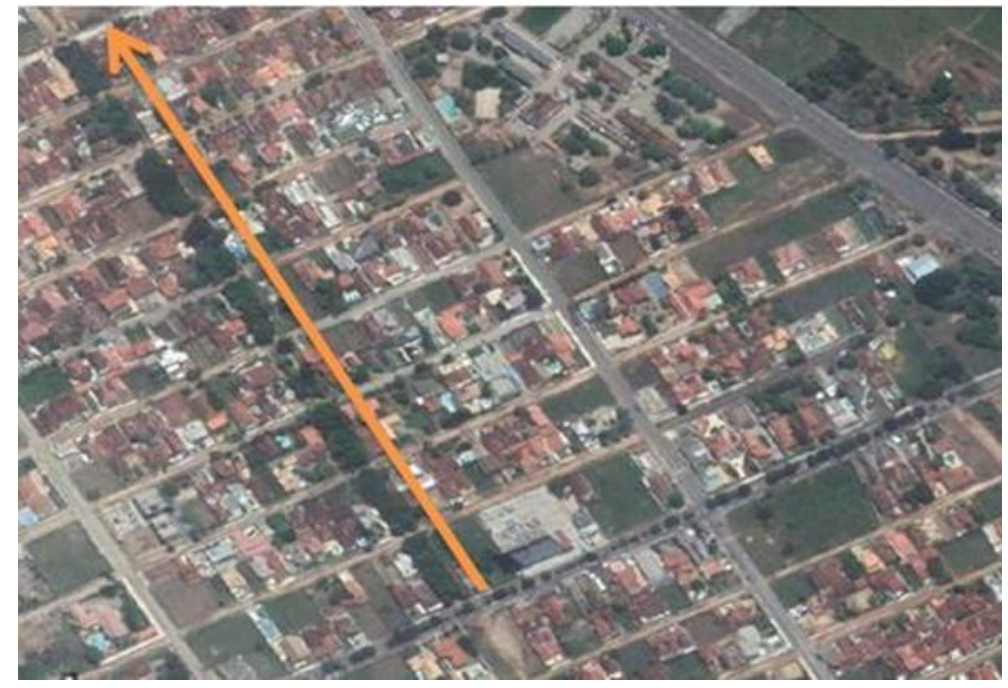

Fonte: Adaptado do Google Maps (2019).

Figura 2. Detalhe da extensão da Área Verde D. Constatino Luers (seta laranja), na malha urbana de Arapiraca-AL

Figure 2. Detail of the extension of the Green Area D. Constatino Luers (orange arrow), in the urban mesh of Arapiraca-AL

A área verde integra uma região com maior valor agregado na cidade de Arapiraca, cuja infraestrutura favorece a prática de atividades físicas, o lazer contemplativo e a recreação, além de possuir ampla arborização e bom aspecto estético-paisagístico (SILVA; GOMES, 2013).

\section{Coleta e análise dos dados}

A abordagem aos entrevistados seguiu a técnica de amostragem não probabilística e por acessibilidade ou conveniência, conforme os seguintes critérios: ser frequentador da Área Verde Dom Constantino Luers, estar disposto a participar deste estudo e ter idade mínima de 12 anos, ou seja, a amostragem partiu da fase de pré-adolescência por acreditar no discernimento dos participantes, a partir dessa idade. Foi considerado frequentador, quem estava praticando caminhada, corrida, contemplação da paisagem, ou qualquer outra atividade de uso do espaço público, sem restrições (ZARDIN et al., 2017). Embora a amostragem não tenha sido probabilística, o quantitativo de entrevistados foi uma amostra representativa ao nível de $95 \%$ de confiança, com margem de erro de 13\%, considerando-se que a população de Arapiraca é estimada em 230.417 habitantes.

As coletas foram efetuadas por meio de entrevistas, no período de abril a maio de 2019, em turnos diferentes (manhã e tarde) para ampliar o esforço amostral, a partir da aplicação de um questionário com perguntas objetivas (com múltipla escolha) e subjetivas (Figura 3), além da realização de algumas observações, em campo. A partir disso, foram 
obtidas informações relacionadas ao perfil sociodemográfico, aos hábitos de utilização da Área Verde pelos frequentadores e percepção ecológica e conservacionista dos mesmos.

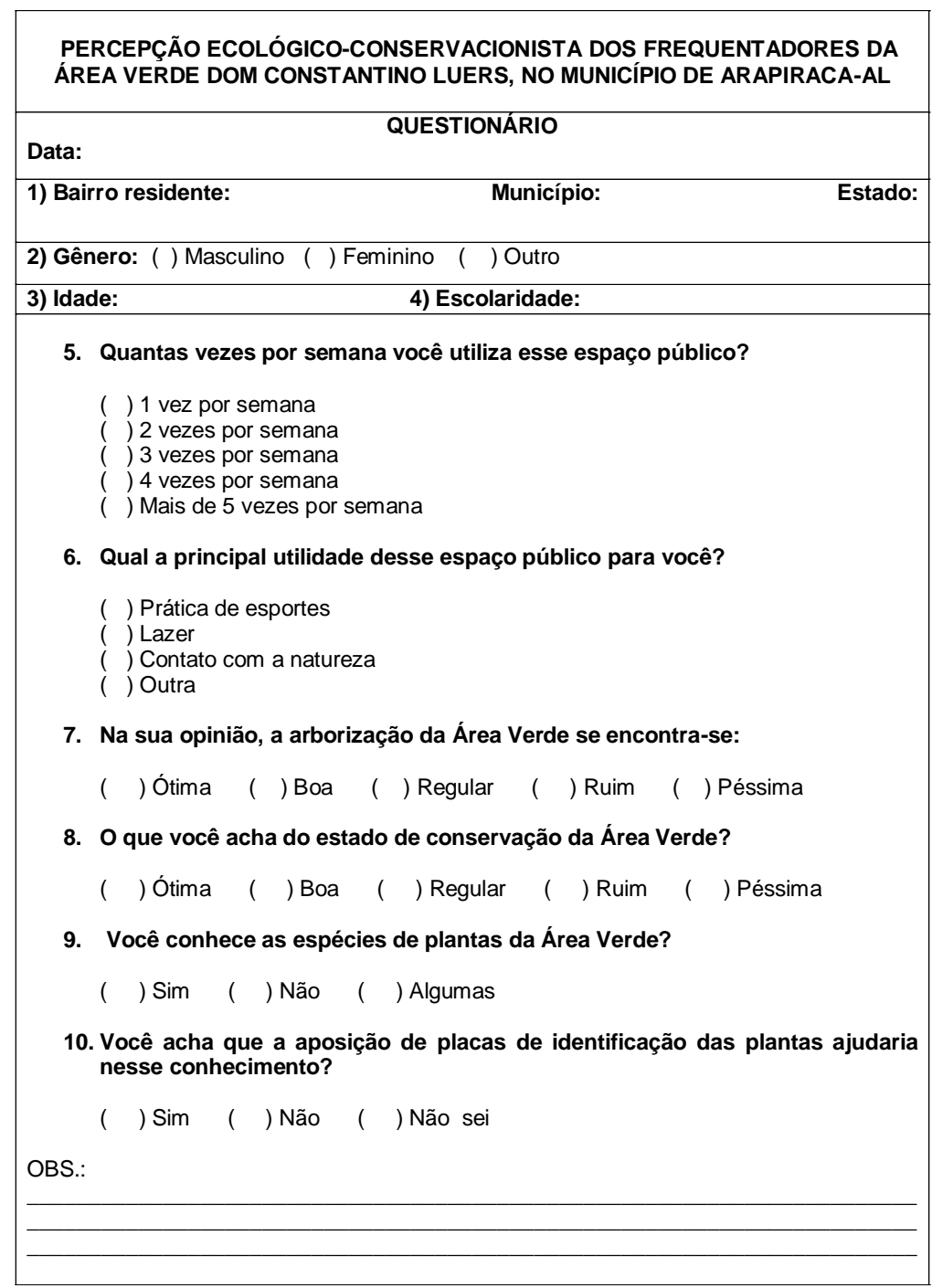

Figura 3. Questionário aplicado aos frequentadores da Área Verde D. Constantino Luers Figure 3. Questionnaire applied to visitors of the Green Area D. Constantino Luers

O Questionário foi organizado de modo que contemplasse as seguintes variáveis do perfil sociodemográfico: sexo, faixa etária, escolaridade e local de residência dos frequentadores. Quanto as variáveis relativas às formas de utilização da Área Verde, foram consideradas: frequência de uso ( 1 vez a mais de 5 vezes por semana) e forma de utilização do espaço. E por último, têm-se as variáveis relacionadas à percepção ecológica e conservacionista: percepções sobre a arborização (ótima, boa, regular, ruim e péssima), o estado de conservação da Área Verde (ótima, boa, regular, ruim e péssima), o conhecimento das espécies vegetais (sim, não e algumas) e a necessidade de identificação das plantas (sim, não e não sei). 
A organização dos dados obtidos foi realizada no programa Microsoft Excel for Windows $^{\circledR}$. A análise dos dados foi efetuada por meio de estatística descritiva e disposta em três seções para melhor compreensão, de acordo com metodologia adaptada (ZARDIN et al., 2017): perfil sociodemográfico dos frequentadores, hábitos de utilização e percepção ecológica e conservacionista dos frequentadores.

\section{RESULTADOS E DISCUSSÃO}

\section{Perfil sociodemográfico}

Foram aplicados, no total, 56 questionários. Dentre os entrevistados, 57,15\% foram do sexo feminino. Esse dado diverge do encontrado em outros estudos, que indicam uma maior frequência do público masculino quando comparado ao feminino (BRUN et al., 2010; ZARDIN et al., 2017). Sugere-se que a menor frequência do público feminino pode estar associada à sensação de insegurança na área, como relatado em um estudo semelhante realizado em outro espaço público de Arapiraca, o Bosque das Arapiracas (GOMES JÚNIOR, 2016).

Com relação a idade dos indivíduos que participaram da pesquisa, 44,64\% estavam na faixa etária de 50 a 69 anos de idade (Tabela 1), mas a variação etária vai de 18 a 89 anos de idade.

Tabela 1. Frequência relativa da faixa etária dos frequentadores entrevistados na Área Verde D. Constantino Luers, em Arapiraca-AL

Table 1. Relative frequency of age group of the interviewed visitors in the Green Area D. Constantino Luers, in Arapiraca-AL

\begin{tabular}{c|c}
\hline Faixa etária dos frequentadores & Frequência (\%) \\
\hline $18-29$ & 15,42 \\
\hline $30-49$ & 29,35 \\
\hline $50-69$ & 44,64 \\
\hline $70-89$ & 10,59 \\
\hline
\end{tabular}

Em um estudo realizado em Mocajuba-PA, constatou-se uma grande variação de idade entre seus entrevistados (entre 15 e 81 anos de idade), fato justificado devido as entrevistas terem sido realizadas nos turnos matutino, vespertino e noturno (BARROS et al., 2018), o que não ocorreu neste estudo, já que a coleta de dados ocorreu pela manhã e pela tarde, ou seja, não contemplou o período noturno.

Quanto ao nível de escolaridade dos entrevistados, este foi muito variado, contemplando desde o não letrado até o pós-graduado. A maioria dos frequentadores da Área Verde D. Constantino Luers possui o ensino médio completo (25,5\%), seguido por 
frequentadores com ensino médio incompleto (18\%), porém os menores índices de escolaridade foram representados pelos participantes que possuem pós-graduação $(3,5 \%)$ e pelos que são não letrados (3\%) (Figura 4).

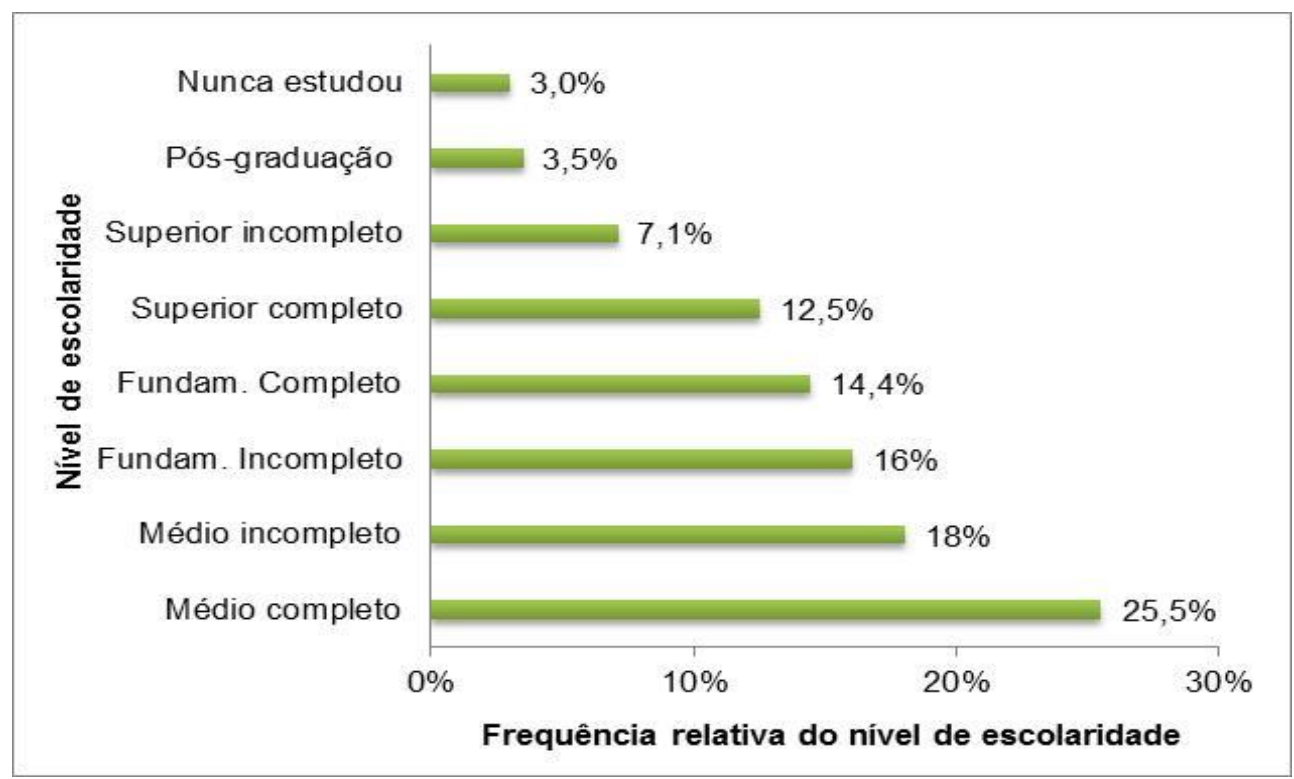

Figura 4. Frequência relativa da escolaridade dos frequentadores entrevistados na Área Verde D. Constantino Luers, em Arapiraca-AL

Figure 4. Relative frequency of schooling of the interviewed visitors in the D. Constantino Luers Green Area, in Arapiraca-AL

A maior utilização de espaços comuns, independentemente do sexo, da idade e do nível de instrução de seus frequentadores, pode ser explicada pelos benefícios relativos à qualidade de vida que esses locais podem oferecer à população (BARROS et al., 2018).

Quanto à questão de residência dos frequentadores, foi possível verificar o raio de influência da Área Verde, pois todos os entrevistados residiam em 10 localidades diferentes, sendo oito bairros, um povoado e um município circunvizinho. Os bairros Novo Horizonte, Itapoã, Brasília e Santa Esmeralda, juntos, representaram 73\% dos frequentadores. Por outro lado, os frequentadores oriundos de locais mais afastados como o município de Craíbas e o Povoado Poço da Pedra apresentaram menor percentual (Figura 5). 


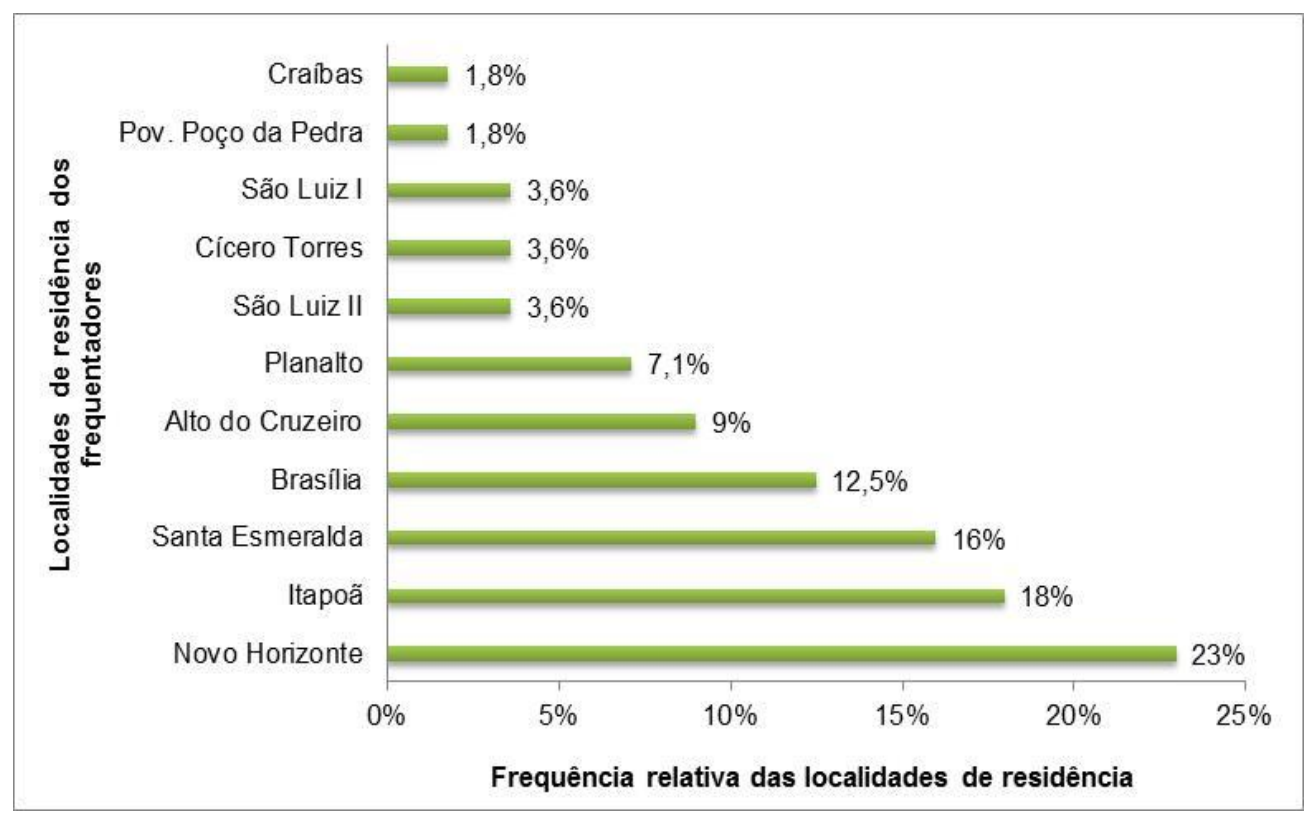

Figura 5. Frequência relativa das localidades onde residem os frequentadores da Área Verde D. Constantino Luers, em Arapiraca-AL

Figure 5. Relative frequency of localities where the visitors reside of the Green Area D. Constantino Luers, in Arapiraca-AL

Pode-se inferior que, o motivo para a alta frequência dos moradores dos bairros Novo Horizonte, Itapoã, Brasília e Santa Esmeralda deve-se a proximidade desses bairros com a Área Verde, uma vez que esta atravessa nos bairros Novo Horizonte e Santa Esmeralda, ao passo que os bairros Itapõa e Brasília também ficam no entorno desse espaço público. Isso demonstra que essa contiguidade com os bairros pode tornar a Área Verde mais atrativa para visitação e prática de atividades físicas, como caminhadas (Figura 6).
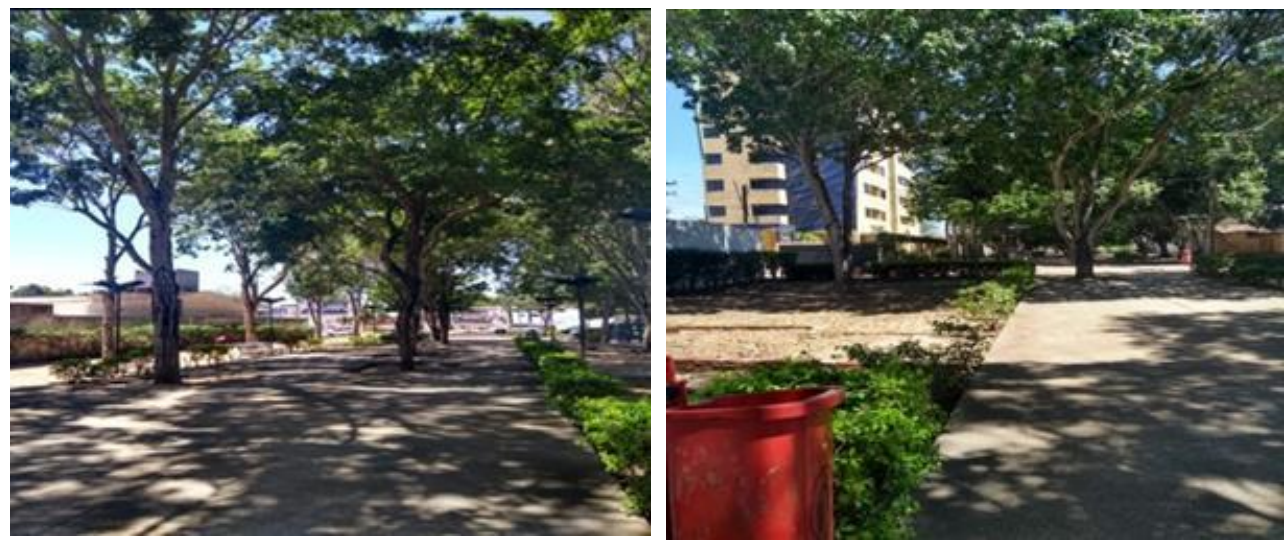

Figura 6. Vista frontal da Área Verde D. Constantino Luers, em Arapiraca-AL Figure 6. Front view of the Green Area D. Constantino Luers, in Arapiraca-AL

Os dados obtidos são similares àqueles contidos em um estudo efetuado na cidade de Cuiabá (MT), no Parque Municipal Lagoa Encantada, onde 80,9\% dos visitantes eram 
moradores de bairros circunvizinhos (BORGES et al., 2017) e, em um estudo realizado em Curitiba (PR), onde 78,9\% dos frequentadores do Parque Municipal São Lourenço eram de bairros próximos (ZARDIN et al., 2017). Em suma, os dados analisados indicam que a Área Verde é relevante para os moradores do entorno, mas também para a população residente em outras áreas, já que, aproximadamente $27 \%$ de seus frequentadores moram em outras localidades. Todavia, esse espaço público constitui um local para usufruto de um grupo específico de frequentadores, tendo em vista sua localização privilegiada, margeada por uma população de alta renda (SILVA; GOMES, 2013).

\section{Hábitos de utilização da Área Verde D. Constantino Luers}

Quando questionados em relação a frequência de uso da Área Verde, foi verificado, por exemplo, que $14 \%$ dos frequentadores a usam quatro vezes por semana e $50 \%$ a usam cinco vezes por semana, ou seja, 64\% dos entrevistados frquentam a Área Verde entre quatro e cinco vezes por semana (Figura 7), o que diverge dos resultados encontrados, por exemplo, em outro estudo, onde $64 \%$ de seus entrevistados frequentavam um parque municipal entre duas e três vezes por semana (ZARDIN et al., 2017). A representatividade da frequência de uso da Área Verde pode ser justificada devido ao fato de cerca de $73 \%$ de seus frequentadores residirem nas imediações da área.

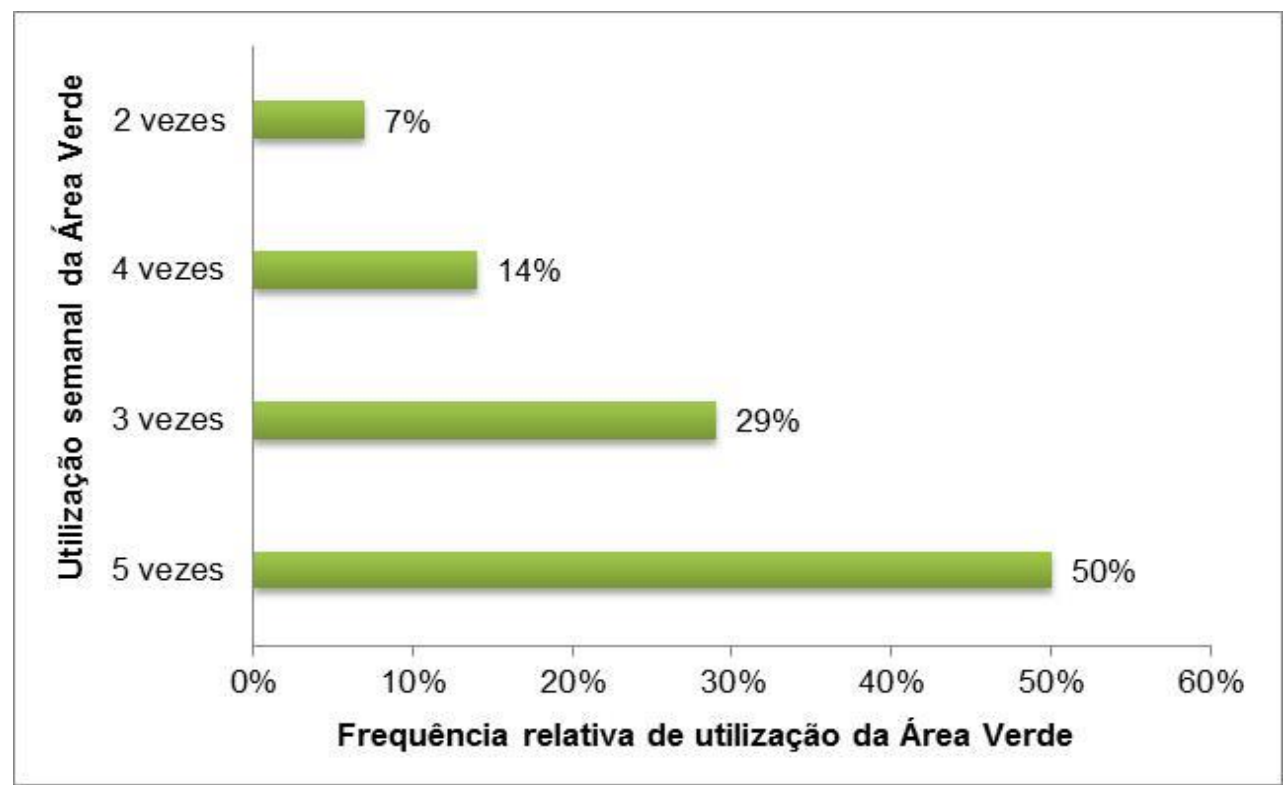

Figura 7. Frequência relativa de utilização semanal da Área Verde D. Constantino Luers, em Arapiraca-AL Figure 7. Relative frequency of weekly use of D. Constantino Luers Green Area in Arapiraca-AL 
Em relação a utilização do espaço pelos frequentadores, isto é, as formas de uso da Área Verde, 50\% afirmaram que a utilizam para a prática de esportes e 28,6\% para o lazer, embora também a utilizem para a contemplação da natureza e/ou outras finalidades não especificadas (Figura 8).

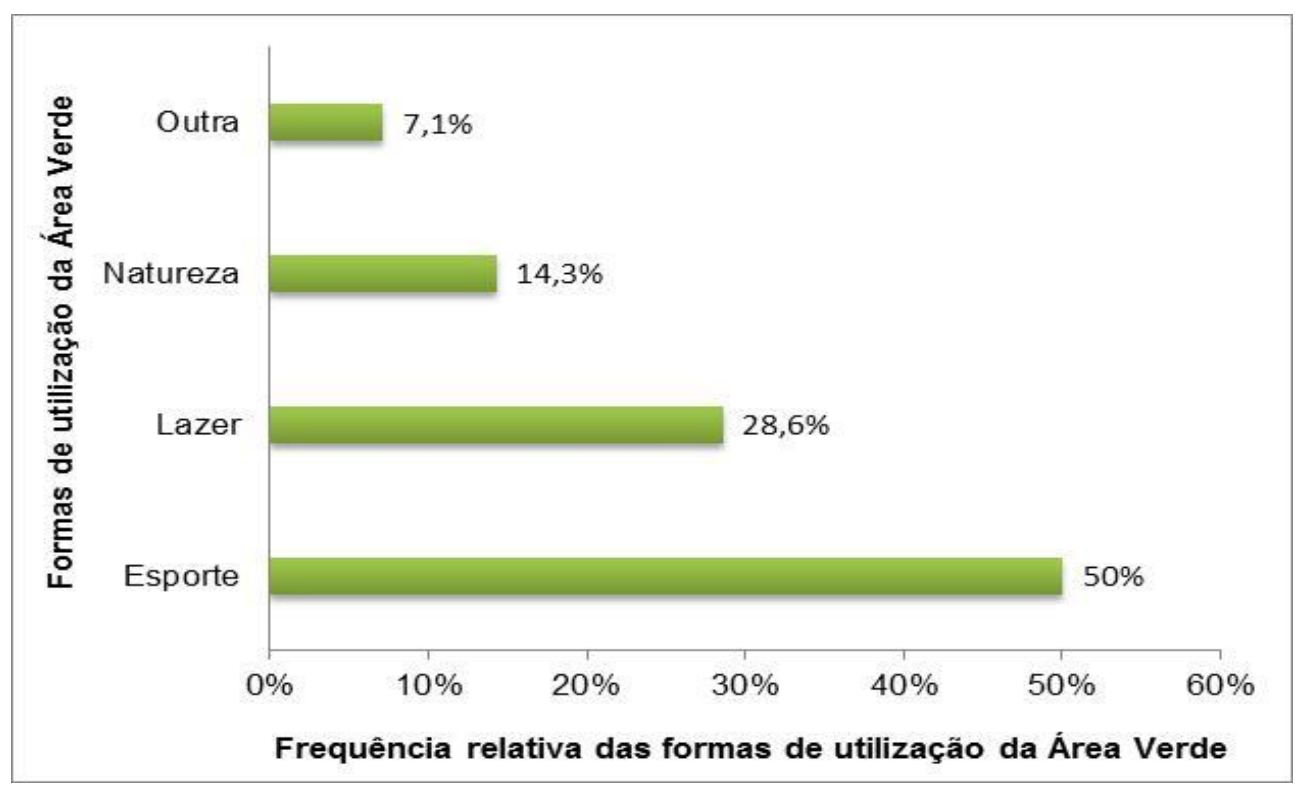

Figura 8. Frequência relativa das formas de utilização da Área Verde D. Constantino Luers, em Arapiraca-AL

Figure 8. Relative frequency of the ways of use of D. Constantino Luers Green Area, in Arapiraca-AL

Estudos realizados em diferentes cidades do Brasil, especificamente, em Recife (PE), em Piracicaba (SP) e em Passo Fundo (RS) concluiram que os frequentadores de áreas verdes públicas tendem a utilizar, comumente, esses locais para a prática de esportes, lazer, recreação, caminhadas/passeios, contato ou contemplação da natureza, convívio social, entre outros (MEUNIER, 2009; BRUN et al., 2010; HOMRICH et al., 2013).

\section{Percepção ecológica e conservacionista}

Na percepção de 39\% dos frequentadores, a arborização da Área Verde está em condição regular, embora para 50\% a arborização está em condições satisfatórias (categorias ótima e boa) (Figura 9) para suas atividades, mas considerando-se as observações efetuadas em campo, vale ressaltar que, as opiniões dos entrevistados quanto a arborização se restringiram ao aspecto físico da vegetação, ou seja, referiram-se a sua quantidade e/ou a sua estética. 


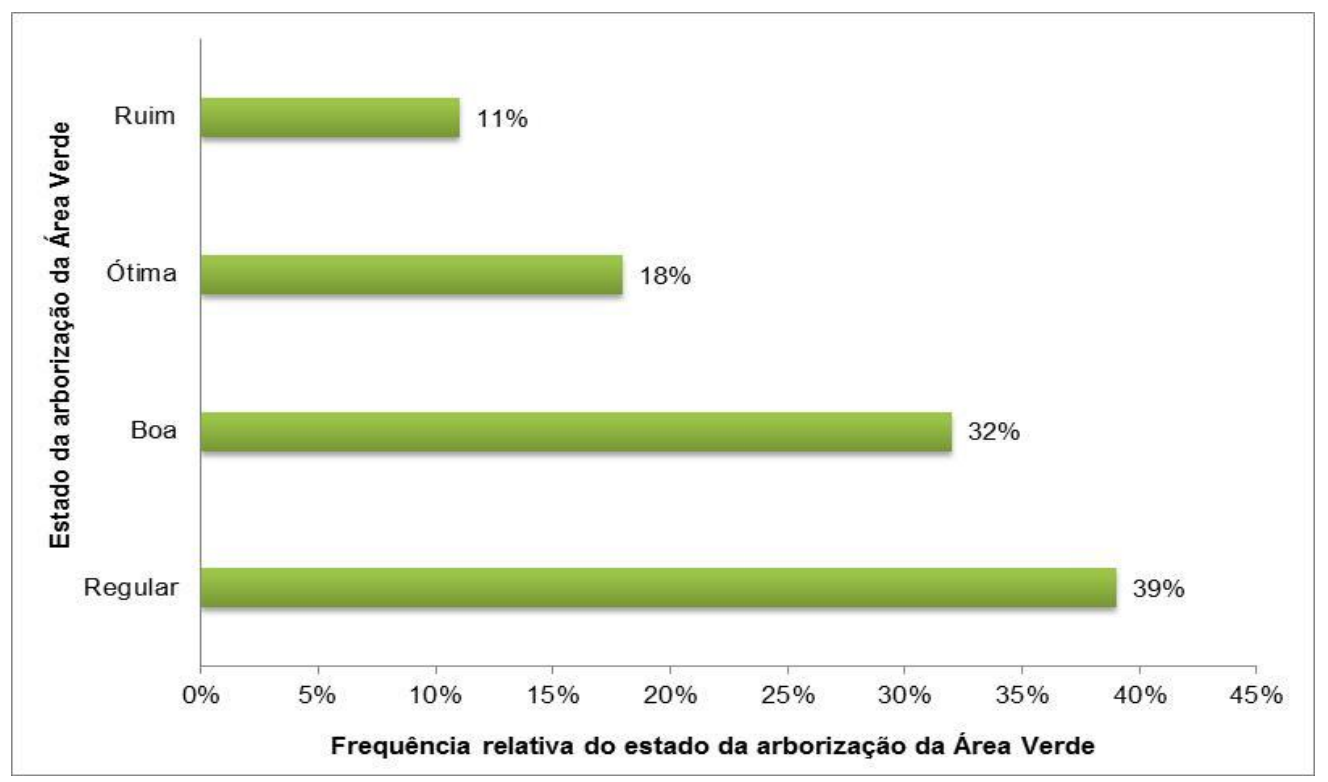

Figura 9. Frequência relativa do estado da arborização da Área Verde D. Constantino Luers, em Arapiraca-AL

Figure 9. Relative frequency of afforestation status of D. Constantino Luers Green Area in Arapiraca-AL

A vegetação é um elemento importante para a garantia de alguns benefícios ambientais, a exemplo da qualidade do ar, qualidade sonora, conforto térmico, eliminação ou diminuição do risco de enchentes, sensibilização ambiental ou Educação Ambiental, lazer, ou seja, é, habitualmente, relacionada ao discurso da qualidade de vida nas cidades (PINA; SANTOS, 2012) e, por isso, assume importante função socioambiental.

Durante a entrevista, frequentadores comentaram que algumas árvores estavam danificando as calçadas e os caminhos da Área Verde, o que indica que podem ter ocorrido falhas no planejamento do plantio das espécies vegetais, por parte dos órgãos públicos competentes. Sabe-se que, no processo de arborização, deve-se considerar o tipo de solo e o clima das cidades, além da escolha das espécies adequadas às diferentes condições regionais (SILVA, 2012), mas também considerar os espaços públicos, pois a vegetação não pode entrar em conflito com equipamentos urbanos, como calçadas e/ou passeios, sistemas de iluminação, fiações elétricas, etc.

Sobre a conservação da Área Verde, foram verificadas diferentes percepções, por exemplo, enquanto $23 \%$ dos frequentadores concordaram que está em bom estado, $35 \%$ disseram que está em estado regular (Figura 10). 


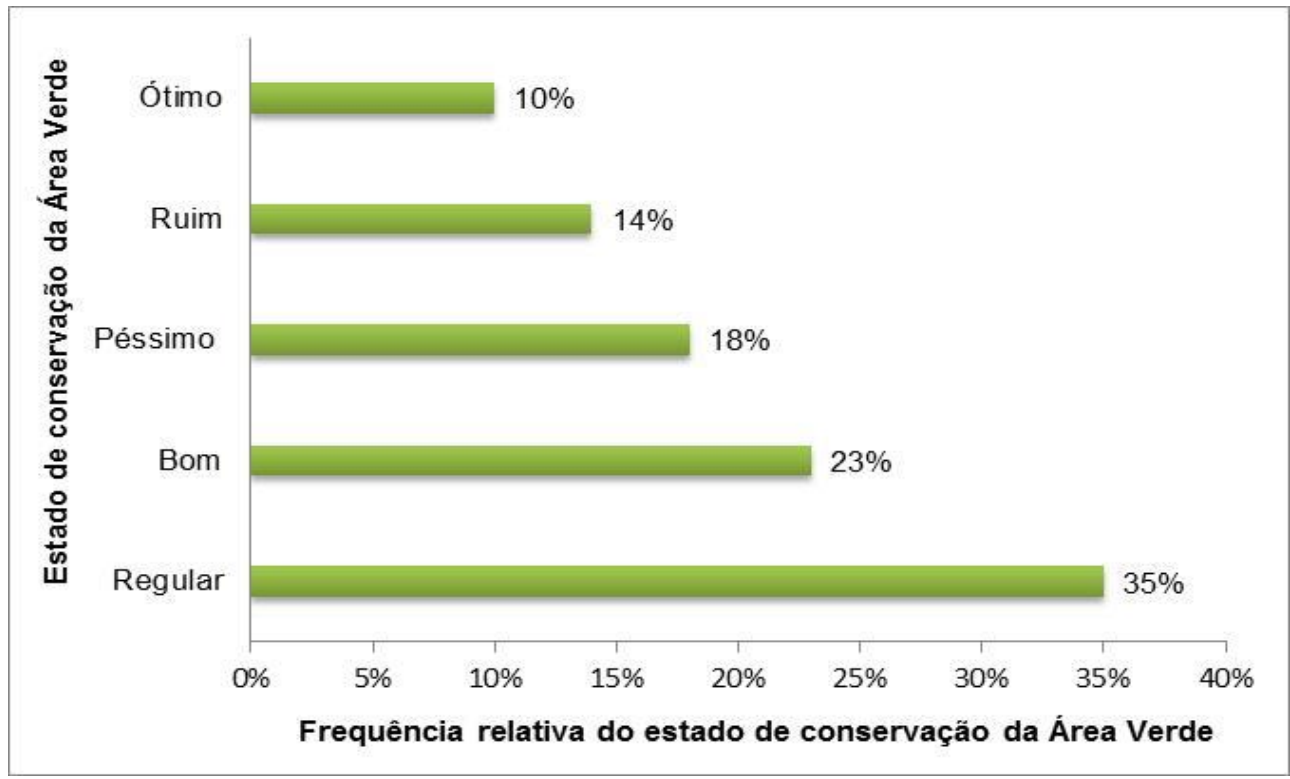

Figura 10. Estado de conservação da Área Verde D. Constantino Luers, em Arapiraca-AL Figure 10. State of conservation of the Green Area D. Constantino Luers, in Arapiraca-AL

Vale ressaltar que, o ambiente físico exerce grande influência na percepção, na atitude e na visão de mundo dos sujeitos, interferindo na interpretação dos indícios visuais e até na estruturação de mundo pela atividade mental do indivíduo (COSTA; COLESANTI, 2011).

Outro questionamento realizado aos participantes deste estudo refere-se ao conhecimento das espécies vegetais presentes no espaço público, onde $45 \%$ informaram que não conhecem nenhuma espécie, 32\% afirmaram conhecer algumas pelo nome popular (craibeira e ipê) e, 23\% disseram que conhecem a maioria dos tipos de plantas que existe na Área Verde.

Diante do questionamento acima, procurou-se saber dos entrevistados sobre a necessidade da colocação de placas de identificação nas plantas existentes na área. Para 78\% dos frequentadores, a colocação dessas placas pode facilitar a identificação, para 18\% essa estratégia é indiferente e para $4 \%$ as placas não facilitariam a identificação das plantas. Inferese que, essa identificação por meio da colocação de placas pode ser uma estratégia viável para auxiliar no conhecimento das espécies vegetais do local e, concomitantemente, no processo de Educação Ambiental, com o intuito de sensibilizar os frequentadores quanto a conservação da Área Verde. 


\section{CONCLUSÕES}

A Área Verde D. Constantino Luers é frequentada por pessoas de diferentes faixas etárias, níveis de escolaridade e que residem, sobretudo, em suas proximidades. Este fato pode ser um indicativo da relevância desse espaço público, destinado a diferentes usos pela população que o frequenta. Todavia, após a aplicação do questionário e da análise dos dados, foi possível entender que há alguns aspectos que causam insatisfação quanto às características gerais da Área Verde, já que os frequentadores ressaltaram a necessidade de melhorias nesse local. Por outro lado, os entrevistados, em geral, demonstraram apreço pelo local e reconheceram a importância e representatividade da área, o que indica uma percepção crítica dos frequentadores.

$\mathrm{Na}$ análise da percepção ecológica e conservacionista dos entrevistados, revelou-se que os mesmos desejam melhorias na arborização, já que a maioria a considerou regular (quando analisada por categoria), assim como no estado de conservação da Área Verde, também considerado regular.

Neste estudo, os dados obtidos reforçam a necessidade de um planejamento para melhoria da arborização na Área Verde e a necessidade de meios que sensibilizem a população frequentadora sobre a importância desse espaço público, por exemplo, por meio de medidas como a implantação de placas de identificação das espécies vegetais.

\section{AGRADECIMENTOS}

As autoras agradecem a Nathália Oliveira de Amorim e Mylena Estelina Gomes Cavalcante pelo auxílio durante a coleta de dados em campo, aos entrevistados que aceitaram participar deste estudo e aos avaliadores pelas sugestões de melhorias no manuscrito.

\section{REFERÊNCIAS}

BARROS, V. S.; MARTINS, C. M.; SANTOS, M. A. S.; REBELLO, F. K.; MONTEIRO, C. W. B.; MESQUITA, I. S. B. Avaliação da organização arbórea e a percepção dos usuários das praças do município de Mocajuba, Estado do Pará, Brasil. Revista da Sociedade Brasileira de Arborização Urbana, Piracicaba, v.13, n.3, p. 01-12, 2018.

BORGES, S. da V.; MELO-SOUSA, R.A.T. de; PASA, M.C. Percepção ambiental e aspectos etnobotânicos no Parque Municipal Lagoa Encantada, Cuiabá - MT. Engenharia Ambiental, Espírito Santo do Pinhal, v. 14, n. 2, p. 81-93, 2017. 
BRUN, F. G. K.; DOBBERT, L. Y.; SERVOLO-FILHO, H. J.; ZAIA, H. B. A.; SILVA-FILHO, D. F. Percepção dos usuários em relação ao conforto ambiental de duas áreas verdes de Piracicaba - SP. Revista da Sociedade Brasileira de Arborização Urbana, Piracicaba, v. 5, n.3, p.59$81,2010$.

COSTA, R. G. S.; COLESANTI, M. M. A contribuição da percepção ambiental nos estudos das áreas verdes. Ra'e Ga - O Espaço Geográfico em Análise, Curitiba, v. 22, p. 238-251, 2011.

DIAS, F. O desafio do espaço público nas cidades do século XXI. Arquitextos, São Paulo, 061, 05, Vitruvius, 2005. Disponível em: <http://www.vitruvius.com.br/revistas/read/arquitextos/ 06.061/453>. Acesso em: 06 out. 2019.

DORIGO, T. A.; LAMANO-FERREIRA, A. P. N. Contribuições da percepção ambiental de frequentadores sobre praças e parques no Brasil (2009-2013): revisão bibliográfica. Revista de Gestão Ambiental e Sustentabilidade, São Paulo, v. 4, n. 3, p. 31-45, 2015.

GOMES JÚNIOR, J. S. Produção e uso do espaço público em Arapiraca, Alagoas: uma avaliação pós-ocupação do Parque Municipal Ceci Cunha e do Bosque das Arapiracas. 2016. 119f. Dissertação (Mestrado em Arquitetura e Urbanismo) - Universidade Federal de Alagoas, Maceió, 2016.

GOMES, M. A. S.; SILVA, R. N.; SILVA, J. C. S.; SILVA, T. G. F. Caracterização e análise dos espaços públicos da cidade de Arapiraca-AL-Brasil. Revista Ateliê Geográfico, Goiânia, v. 6, n. 4, p. 137-157, 2012.

GOMES, M. A.S.; SILVA, R. N. da.; FERREIRA, R. V. Mudanças socioespaciais urbanas em Arapiraca-AL na aurora do século XXI. Espaço \& Geografia, Brasília, v. 18, v. 1, p. 25-53, 2015.

HOMRICH, R. T.; GONÇALVES, I. L.; BORGES, A. C. P.; ZANIN, E. M.; VALDUGA, A. T. Caracterização e percepção de um espaço verde urbano em uma cidade de porte médio, Rio Grande do Sul - Brasil. Perspectiva, Erechim, v. 37, Edição Especial, p. 41-47, 2013.

IBGE (INSTITUTO BRASILEIRO DE GEOGRAFIA E ESTATÍSTICA). Panorama de Arapiraca. 2018. Disponível em: <https://cidades.ibge.gov.br/brasil/al/arapiraca/panorama>. Acesso em: 06 jul. 2019.

JATOBÁ, S. U. S. Urbanização, meio ambiente e vulnerabilidade social. Boletim Regional, Urbano e Ambiental (IPEA), Brasília, p. 141-148, 2011.

LOBODA, C. R.; ANGELIS, B. L. D. de. Áreas verdes públicas urbanas: conceitos, usos e funções. Revista Ambiência, Guarapuava, v.1, n.1, p. 125-139, 2005.

LONDE, P. R.; MENDES, P. C. A influência das áreas verdes na qualidade de vida urbana. Revista Brasileira de Geografia Médica e da Saúde, Uberlândia, v. 10, n. 18, p. 264 - 272, 2014.

MARIN, A. A. A Percepção ambiental e imaginário dos moradores do município de Jardim/MS. São Carlos, 2003. 317f. Tese (Doutorado em Ciências Biológicas) - Universidade Federal de São Carlos, São Carlos, 2003.

MASCARENHAS, J. C.; BELTRÃO, B. A.; SOUZA JÚNIOR, L. C. (Org.). Projeto cadastro de fontes de abastecimento por água subterrânea: diagnóstico do município de Arapiraca, 
Estado de Alagoas. Ministério de Minas e Energia. Secretaria de Geologia, Mineração e Transformação Mineral. Recife: CPRM/PRODEEM, 2005. 13p.

MEUNIER, I. M. J. Percepções e expectativas de moradores do Grande Recife-PE em relação aos parques urbanos. Revista da Sociedade Brasileira de Arborização Urbana, Piracicaba, v.4, n.2, p.35-43, 2009.

PINA, J. H. A.; SANTOS, D. G. dos. A influência das áreas verdes urbanas na qualidade de vida: o caso dos Parques do Sabiá e Victório Siquierolli em Uberlândia-MG. Ateliê Geográfico, Goiânia, v. 6, n. 1, p.143-169, 2012.

PMA (PREFEITURA MUNICIPAL DE ARAPIRACA). Pontos Turísticos. Disponível em: $<$ http://web.arapiraca.al.gov.br/turismo/pontos-turisticos/>. Acesso em: 05 jul. 2019.

SILVA, R. N. Caracterização e análise qualiquantitativa da arborização em praças da área central da cidade de Arapiraca, AL. Revista da Sociedade Brasileira de Arborização Urbana, Piracicaba, v.7, n.2, p. 102-115, 2012.

SILVA, R. N.; GOMES, M. A. S. Comparação qualiquantitativa da arborização em espaços públicos da cidade de Arapiraca-AL. Revista da Sociedade Brasileira de Arborização Urbana, Piracicaba, v.8, n.2, p. 104-117, 2013.

SOARES, J. A. S.; ALENCAR, L. D. de; CAVALCANTE, L. P. S.; ALENCAR, L. D. de. Impactos da urbanização desordenada na saúde pública: leptospirose e infraestrutura urbana. POLÊM!CA, Rio de Janeiro, v. 13, n. 1, p. 1006-1020, 2014.

ZARDIN, M. C.; OLIVEIRA, J. D. de.; ARTHUSO, J. P.; BIONDI, D. Perfil e percepção dos frequentadores do Parque Municipal São Lourenço de Curitiba - PR. Revista da Sociedade Brasileira de Arborização Urbana, Piracicaba, v.12, n.3, p. 37-50, 2017. 